THE KURUME MEDICAL JOURNAL Vol. 4, No. 1, 1957

\title{
THE EFFECTS OF SEVERAL HYPOTENSIVE DRUGS, ESPECIALLY THEIR SYNERGISTIC AND ANTAGONISTIC EFFECTS ON RATS
}

\author{
NOBUFUSA NATORI, YASUO KAKEHASI AND \\ NOBUYUKI NAGASAKI \\ Department of Pharmacology*, Kurume University School of Medicine, \\ Kurume-shi, Japan
}

\begin{abstract}
A number of hypotensive agents have been introduced during recent years for the treatment of hypertension and it has been reported from the clinical experiences that the combined treatments of several hypotensive drugs are more effective than the single one respectively. However, there have been few reports in which the combined effects of them are comparatively investigated on laboratory animals pharmacologically.

The present report is concerned with the intensity and duration of several hypotensive drugs and their synergistic or antagonistic effects on normotensive or renal hypertensive rats.
\end{abstract}

\section{ME'THOD}

The experiments were carried out on the five or more albino rats of Wister strain (body weight, 120-220g) in each doses, selected at random without regard to sex and the same rats were used at intervals of at least one week after the previous experiments. They were anesthetized with subcutaneously injected urethane $(0.5 \mathrm{~g} / \mathrm{kg})$ at 60 minutes beíore the beginning of experiments. Blood pressure was determined by the plethysmographic tail method of Byrom and Wilson (1938).

The exper:mental renal hypertensive rats were given by the method of Grollman (1955) in which a figure-of-eight ligature was carried out on the bilateral kidney at an interval of one or three weeks. The blood pressure of these animals rose gradually and reached the maximum constant hypertensive level at 2 or 3 months after the operation.

The drugs used in this study were hexamethonium bromid, veratrum viride, 1-hydrazinophthalazine (apresoline) and reserpine. All drugs were diluted by the physiological salt solution, if necessary, and injected subcutaneously. Since the hypotensive effect of reserpine was very gradual and persistent, other drugs were administered after 80 minutes from the injection of reserpine in order to make the peak of both effects

*Director: Prof. N. Nagasaki, M. D. 
coincide.

\section{RESULTS}

1) The comparison of the hypotensive effects on normotensive and renal hypertensive rats.

The $\mathrm{ED}_{50}$ of each drugs on normotensive and renal hypertensive rats are summarized in Table 1. The procedure to determine the $\mathrm{ED}_{50}$ has been described in the previous report (Natori et al., 1956). When the maximum fall in blood pressure over $10 \mathrm{mmHg}$ is observed on more than three within five animals, the dose of the drugs are considered as the $\mathrm{ED}_{50}$. This procedure is statistically examined and found to be suitable for the determination of the $\mathrm{ED}_{50}$.

Except for apresoline, all drugs are demonstrated to be more effective in renal hypertensive than normotensive rats.

TABLE 1

The $E D_{50}$ of each drugs on the normotensive and renal hypertensive rats

\begin{tabular}{|c|c|c|c|c|c|c|c|c|}
\hline \multicolumn{5}{|c|}{ normotensive rat } & \multicolumn{4}{|c|}{ renal hypertensive rat } \\
\hline Drug & $\begin{array}{c}\mathrm{ED}_{\overline{5}} \\
\mathrm{mg} / \mathrm{kg}\end{array}$ & $\mathrm{mf}$ & $\mathrm{t}$ & $\mathrm{p}$ & $\begin{array}{c}\mathrm{ED} \text { 5о } \\
\mathrm{mg} / \mathrm{kg}\end{array}$ & m.f. & $\mathrm{t}$ & $\mathbf{p}$ \\
\hline $\mathrm{C}_{6}$ & 10.0 & 21.8 & 5.08 & $0.01>>0.005$ & 1.0 & 17.6 & 4.99 & $0.01 \gg>0.005$ \\
\hline Apresoline & 0.5 & 21.4 & 2.38 & $0.10>>0.05$ & 0.5 & 27.6 & 2.49 & $0.10>>0.05$ \\
\hline Veratrum & 1.0 & 16.0 & 2.93 & $0.05 \gg>0.025$ & 0.3 & 32.4 & 6.27 & $0.01>>0.005$ \\
\hline Reserpine & 0.1 & 17.0 & 4.95 & $0.05 \gg>0.025$ & 0.05 & 14.2 & 3.88 & $0.025 \gg>0.01$ \\
\hline
\end{tabular}

m.f.: mean value of maximum fall in blood pressure.

2) The relations between the intensity, total duration or duration of maximum fall and doses of the drugs.

Fig. 1-3 are the graphic presentations of them. The intensity of the hypotensive effect of reserpine does not so increase as that of the other drugs, but the duration prolongs remarkably accompanied with the increase of doses. On the contrary, hexamethonium shows that the intensity of the effect increases markedly, but the duration, especially the duration of maximum fall, scarcely prolongs with high doses. Apresoline and veratrum viride belong to the intermediate group.

3) The synergistic or antagonistic effects of the drugs.

Typical results of them are summarized in Fig. 4-7. The reduction in blood pressure in $\mathrm{mmHg}$ are plotted as ordinate against the percentage of the doses of two 


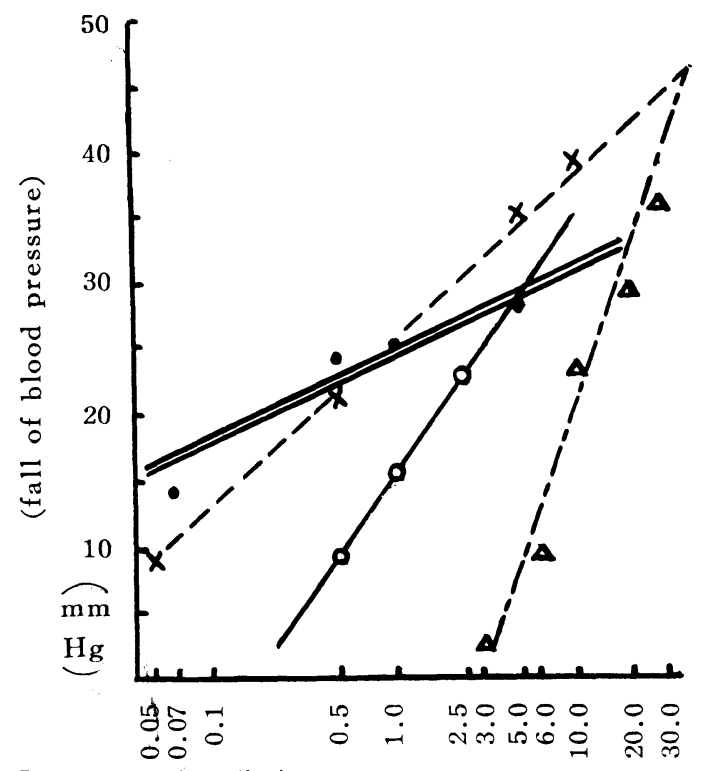

Log Dose $(\mathrm{mg} / \mathrm{kg})$ $\triangle--\triangle$ C $\mathrm{C}_{6}$
$\times--\times$ Apres.
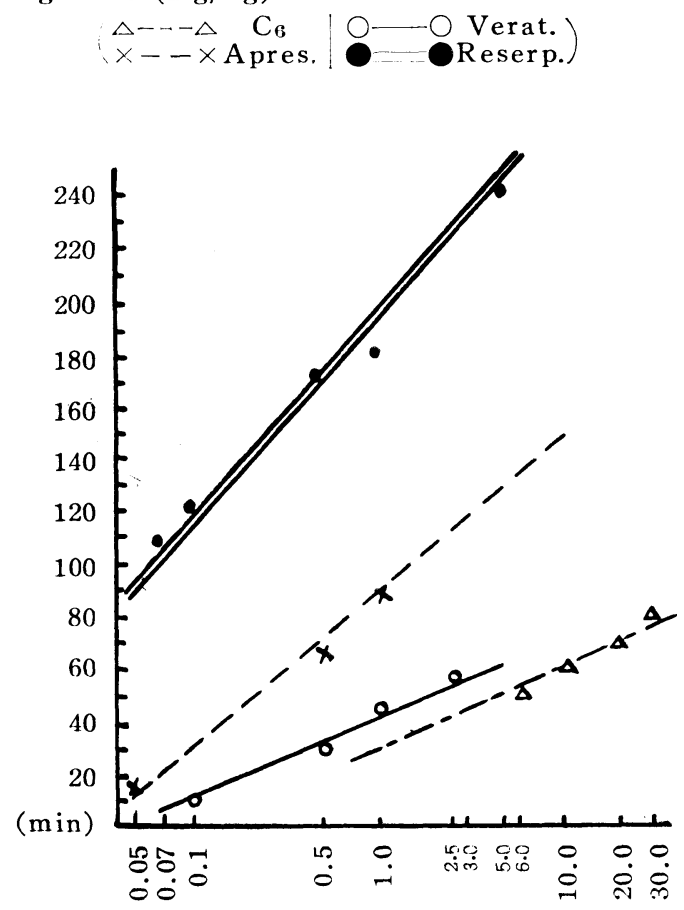

Log Dose $(\mathrm{mg} / \mathrm{kg})$

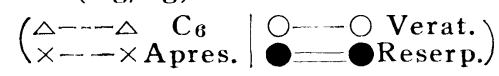

Fig 1. The relation of the intensity of fall in blood pressure to doses. The fall in blood pressure in $\mathrm{mmHg}$ are plotted as ordinates against the logarithmic doses as abscissae.

Fig. 2. The relation of the total duration of fall in blood pressure to doses.

The duration of fall in blood pressure in minute are plotted as ordinates against the logarithmic doses as abscissae. 


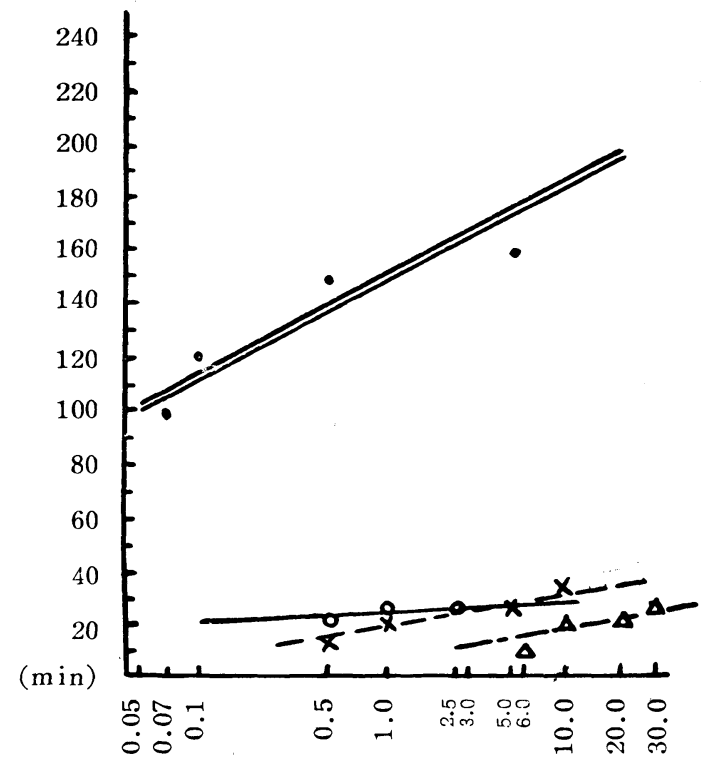

Log Dose $(\mathrm{mg} / \mathrm{kg})$

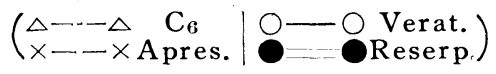

Fig. 3. The relation of the duration of maximum fall in blood pressure to doses.

The duration of fall in blood pressure in minute are plotted as ordinates against the logarthmic doses as abscissae. The time lasting the fall within $5 \mathrm{~mm}$ $\mathrm{Hg}$ from the value of maximal fall in blood pressure was defined as "the duration of maximal fall",

drugs as abscissae. The doses of each drugs are used on the basis of $\mathrm{ED}_{50}$ determined in result 1 .

The hypotensive effect of reserpine plus apresoline is remarkably increased. The mean value of the maximum fall in blood pressure by administration of $\mathrm{ED}_{50}$ of reserpine is $17.0 \mathrm{mmHg}$, and that of apresoline is $21.4 \mathrm{mmHg}$, however, when the doses of $1 / 2 \mathrm{ED}_{50}$ of both drugs are administered the mean value is $31.0 \mathrm{mmHg}$. And so the graphic presentation shows a convex curve (Fig. 4). This fact may suggest that reserpine plus apresoline has a potentiative effect on blood pressure.

While the intensity of the combined effects of reserpine plus veratrum viride or hexamethonium plus apresoline are approximately equivalent to that of $\mathrm{ED}_{50}$ of both drugs and the graphic presentation shows a straight line (Fig. 5 and 6). These results may demonstrated that the combinations are not potentiative but additive.

On the other hand, the combination of hexamethonium plus veratrum viride indicates a sharp contrast with the others. When the doses of $1 / 2 \mathrm{ED}_{50}$ of both drugs are administered, the hypotensive effect is scarcely observed and the graphic presentation describes a concave curve (Fig. 7). However, the moderate hypotensive effect is observed by the combined administration of $25 \%$ of $\mathrm{ED}_{50}$ of hexamethonium plus $75 \%$ of $\mathrm{ED}_{50}$ of veratrum viride. 


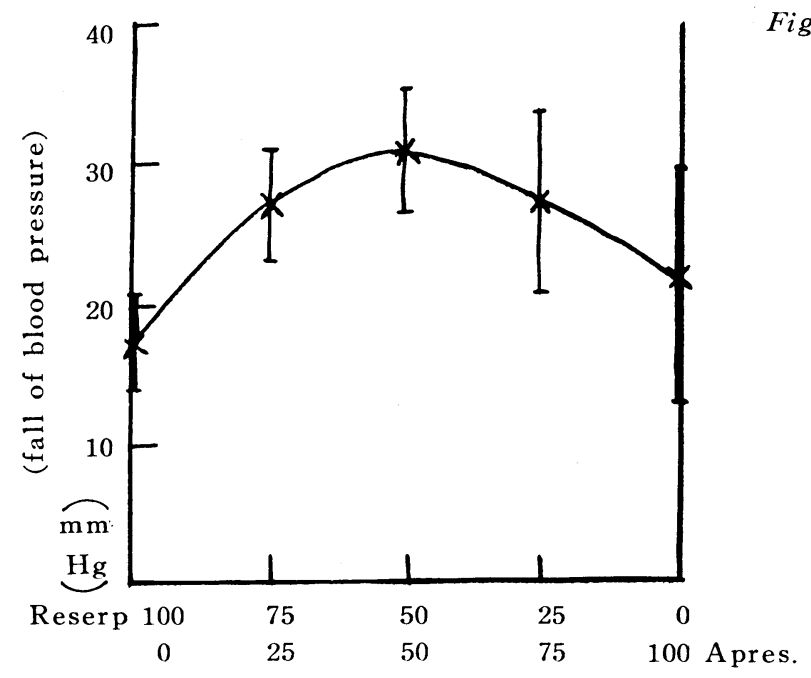

Fig 4. The combined effects of reserpine plus 1 -hydrazinophthalazine in reducing the blood pressure following their injection subcutaneously into the normotensive rats.

The curve is the composite of average results obtained on series of 5 to 10 animals. The reduction in mean arterial blood pressure in $\mathrm{mmHg}$ are plotted as ordinates against the doses as abscissae. The dose in $75 \%, 50 \%, 25 \%$ of EDso were used.

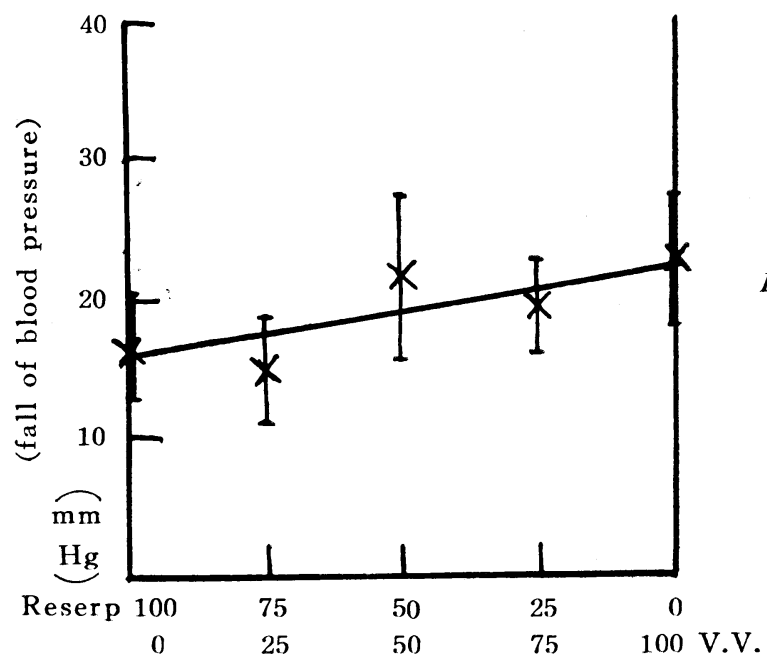

Fig. 5. The combined effects of reserpine plus veratrum $v$. 

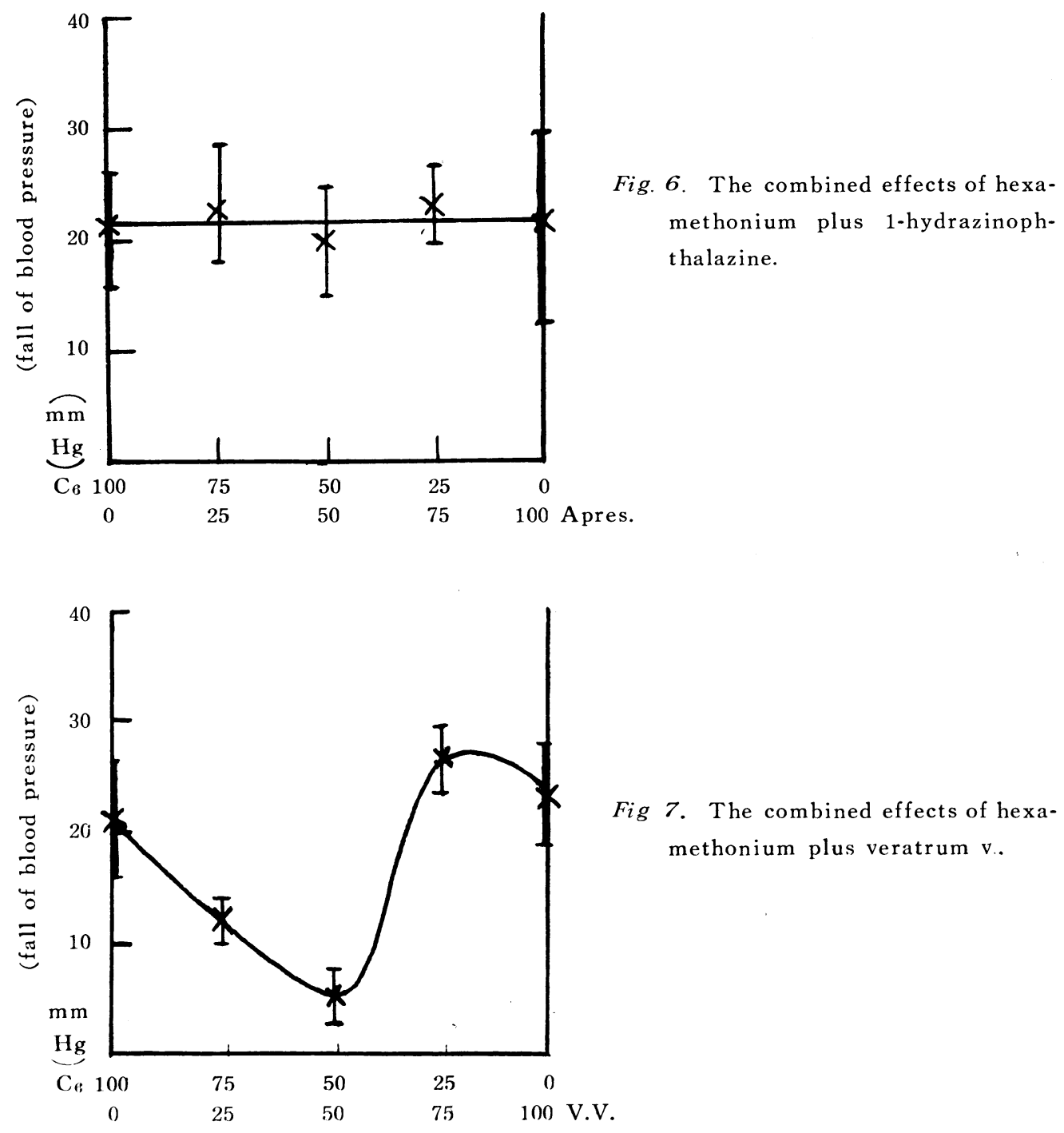

\section{DISCUSSION}

In the previous paper (Natori et al., 1956), it was reported that the procedure to determine the $\mathrm{ED}_{50}$ by the plethysmographic tail method of Byrom and Wilson which we used in this experiments, was suitable for the screening the hypotensive agents and significant statistically. And also the combined effect of the drugs was reported in the other paper (Natori et al., 1957). In the present investigation, the relations 
between the effect and doses, and their synergistic or antagonistic effect have been mainly studied.

The results obtained in this study on rats are identical with many clinical reports and similar to that of Meier and coworkers (1955), who administer the drugs intravenously on rabbits. They described that veratrine belonged in the group in which the intensity of the hypotensive effect was markedly increased with high doses. Among the drugs in the present study, hexamethonium has a most notable tendency to this group.

Apresoline shows a particular properties, namely, the effect in renal hypertensive rats is not more potentiative than that in normotensive unlike other drugs and the total duration of the effect prolongs like that of reserpine but the duration of maximum fall does not prolong so markedly with the increase of doses, as shown by Fig. 2 and 3. These facts may indicate the singularity of the effect of apresoline.

In 1952 Schroeder reported that the combination of hexamethonium and apresoline had a potentiative hypotensive effect, named it "Hyphex" and encoureged the use in the treatment of malignant hypertension. On the other hand, Mc Cubbin et al. (1954) reported that the effect of Hyphex was not potentiative but only additive. In our previous paper, it was reported that Hyphex showed the potentiative effect because the combination of the drugs in doses of $1 / 3 \mathrm{ED}_{50}$ respectively caused a significant fall in blood pressuce. However, the graphic presentation of this study demonstrated that the combination of the two drugs in the rate of various percentage had the approximately equal effect to that of the drugs respectively.

The combination of reserpine plus apresoline was reported to be effective for the treatment of essential hypertension (Kuhns et al., 1954) and has been already placed in the market. In the present investigation, this combination was proved to have a remarkable potentiative effect, especially in case of $1 / 2 \mathrm{ED}_{50}$ respectively.

On the contrary, the combination of hexamethonium plus veratrum viride was indicated to be uneffective. It is natural phenomenon considering to the mechanism of the durgs; the reflex vasodilator action of veratrum and the ganglionic blocking action of hexamethonium. The fact that the combined administration of $25 \%$ ED: of hexamethonium plus $75 \% \mathrm{ED}_{50}$ of veratrum caused a considerable hypotension (Fig. 7), might sustaine this opinion.

\section{SUMMARY}

The effects of several hypotensive drugs injected subcutaneously were compared on normotensive and renal hypertensive rats, and the dose-response relationship was 
analysed. Furthermore, the combined effects of the drugs were investigated and their interesting graphic presentation were obtained.

\section{REFERENCES}

1. BYrom, F. B. And Wilson, C.: A plethysmographic method for measuring systolic blood pressure in the intact rat. J. Physiol., Vol. 93, 301-304, 1938.

2. Grollman, A.: A simplified procedure for inducing chronic renal hypertension in the mammal. Proc. Soc. Exper. Biol. \& Med., Vol. 57, 102-104, 1944.

3. Kuhns, K., Duuranovic, R, Gehrs, C. and Koppen, K.: Comparative clinical investigations of the blood pressure effect of hydrazinophthalazin and the rauwolfia alkaloid. Klin. Wochenschr., Vol. 32, 930-935, 1954

4 Mc Crubin, J. W. and Page, I H.: Modification of the hypotensive action of 1-hydrazinophthalazine (apresoline) by priscoline, hexamethonium and section of the carotid sinus and aortic buffer nerves in normal and renal hypertensive dogs. Amer. J. Med. Sci., Vol. 226, 632-635, 1954

5. Meifr, B., Tripod, J. and Bruni, C.: Quantitative Charakterisierung der Blutdrucksenkung verschiedenartiger hypotensiver Stoffe. Arch. Int. Pharmacodyn. Vol. 101, 158-170, 1955.

6. Natori, N., Mizunoe, M. and Nagasaki, N.: The intensity and duration of the hypotensive effects of several drugs on normotensive and renal hypertensive rats. J. Kurume Med. A., Vol. 19, 1915-1922, 1956 (in Japanese).

7. Natori, N., Kakehashi, Y. and Nagasaki, N.: Combined effects of several hypotensive drugs on normotensive rats. J. Kurume Med A., Vol. 20, 157-160, 1957 (in Japanese).

8. Schrofder, H. A.: Control of hypertension by hexamethonium and 1-hydrazinophthazine. Arch. Int. Med. Vol. 86, 523-540, 1952. 